\section{ORIGINAL RESEARCH}

R. Thiex

A. Williams

E. Smith

R.M. Scott

D.B. Orbach

\title{
The Use of Onyx for Embolization of Central Nervous System Arteriovenous Lesions in Pediatric Patients
}

\begin{abstract}
BACKGROUND AND PURPOSE: The safety and efficacy of Onyx for the embolization of central nervous system (CNS) arteriovenous (AV) lesions have been widely reported in adults. However, data describing the use of this agent in children are limited. This study presents our experience with Onyx in the treatment of CNS AV lesions in pediatric patients.
\end{abstract}

\begin{abstract}
MATERIALS AND METHODS: We retrospectively analyzed clinical and imaging records of 15 pediatric patients who underwent 36 transarterial embolizations by using Onyx for CNS AV lesions, from March 2007 through April 2009 at our institution. Underlying pathologies included brain AV malformations (AVMs) $(n=7)$, vein of Galen malformations $(n=4)$, dural AV fistulas $(n=2)$, and spinal AVMs ( $n=$ 2). For 7 procedures in very high-flow lesions, detachable coils were deployed before Onyx embolization, whereas in 29 procedures, Onyx was the sole embolic agent. The efficacy of embolization was judged by the residuum of AV shunting within the target region.
\end{abstract}

\begin{abstract}
RESULTS: Embolization was complete in 2 patients, nearly complete in 9 patients, and partial (and ongoing) in 4 patients. Following staged embolization, 7 patients underwent surgical resection without significant blood loss and with good functional outcome in all cases. Clinically silent non-target embolization was encountered in 2 of 36 procedures. After 3 of the 36 embolizations, patients developed transient neurologic symptoms, all of which resolved to baseline within 24 hours. There were no non-neurologic adverse events. There was no imaging evidence of infarct or hemorrhage.
\end{abstract}

CONCLUSIONS: Onyx embolization of pediatric CNS AV lesions can be an efficacious treatment technique, with extremely low associated morbidity.

$\mathbf{P}$ ediatric arteriovenous (AV) lesions are congenital and may present at any time during childhood. They comprise a broad panoply of lesions, with risks ranging from neonatal high-output cardiac failure, to ongoing risk of rupture and intracranial hemorrhage, to intermediate-term risk, to normal neurologic development. In each case, treatment-related morbidity and mortality must be weighed against the intrinsic lesional risks. Treatment of pediatric patients_-particularly infants and young children-whether by open surgical or endovascular means, poses unique technical challenges. Embolization has a significant role in the multimodality treatment of central nervous system (CNS) AV malformations (AVMs) and fistulas, either as a definitive treatment or as an adjunct to microsurgery or radiosurgery.

The use of ethylene-vinyl alcohol copolymer dissolved in dimethyl-sulfoxide (DMSO) as an endovascular embolic agent for intracranial AVMs was first described by Taki et $\mathrm{al}^{1}$ and Terada et $\mathrm{al}^{2}$ in the early 1990s. A similar compound, using tantalum powder for radiopacity, is now commercially available as Onyx (ev3, Irvine, California) and is US Food and Drug Administration (FDA)-approved for the preoperative embolization of brain AVMs. ${ }^{3,4}$ Two preparations are currently available for this use: Onyx 34 and Onyx 18, with the former twice as viscous as the latter. Polymerization of Onyx

\footnotetext{
Received May 4, 2009; accepted after revision June 15.
}

From the Departments of Radiology and Neurosurgery (R.T., D.B.O.), Brigham and Women's Hospital, Boston, Massachusetts; Department of Neurosurgery (E.S., R.M.S.) and Neurointerventional Division (A.W., D.B.O.), Children's Hospital Boston, Boston, Massachusetts; and Harvard Medical School (R.T., E.S., R.M.S., D.B.O.), Boston, Massachusetts.

Please address correspondence to Darren Benjamin Orbach, MD PhD, Neurointerventional Radiology, Children's Hospital Boston, 300 Longwood Ave, Boston, MA 02115; e-mail: darren.orbach@childrens.harvard.edu

DOI 10.3174/ajnr.A1786 after intra-arterial injection is based on copolymer precipitation, which depends on diffusion of DMSO out of the solution, allowing a slow and controlled embolization.

We investigated the clinical and anatomic results of Onyx embolization of CNS AVMs and fistulas and report here the largest series to date of Onyx embolizations in the pediatric population. Clinical presentation, angiographic findings, endovascular management, and clinical outcome are presented in a series of 15 patients. Technical aspects that render Onyx injection safe in pediatric patients are stressed, as are anatomic and radiographic features that suggest potential hazards.

\section{Materials and Methods}

Institutional review board approval was obtained for retrospective review of cases for this study.

\section{Patient Demographics}

A data base of all pediatric patients treated by the neurointerventional service at Children's Hospital Boston from March 2007, when the first Onyx procedure was performed, through April 2009 was retrospectively reviewed to identify patients with CNS AVMs and fistulas. The records and angiographic images of these 15 patients (age range, 4 days to 18 years; median age, 3 years; Table 1) were investigated to ascertain the nature and anatomic features of the vascular pathology, clinical presentation, neurologic function throughout treatment, technical details related to the embolizations, and performance of surgical resection.

\section{Angiography Technique}

All procedures were performed by the same surgeon (D.B.O.). Given limitations on contrast-volume administration to pediatric patients as well as a desire to limit fluoroscopic exposure, extensive use was 
Table 1: Clinical presentation before and functional outcome after endovascular therapy

\begin{tabular}{|c|c|c|c|c|c|}
\hline $\begin{array}{l}\text { Patient } \\
\text { No. }\end{array}$ & Age & Sex & Localization & Signs/Symptoms at Presentation & Signs/Symptoms after Treatment \\
\hline 1 & $4 d$ & $M$ & VoG, c & Cardiac failure & Improved cardiac function \\
\hline 2 & $5 \mathrm{mo}$ & M & VoG, $m$ & Prenatal ultrasonic diagnosis & Increased intermittent left-sided exotropia \\
\hline 3 & $7 \mathrm{mo}$ & $\mathrm{F}$ & Dural AVF & $\begin{array}{l}\text { Incidental finding in work-up for subglottic } \\
\text { hemangioma }\end{array}$ & ND \\
\hline 4 & $9 \mathrm{mo}$ & $\mathrm{F}$ & R frontal AVM & $\begin{array}{l}\text { Incidental finding in work-up for family history of } \\
\text { HHT }\end{array}$ & ND \\
\hline 5 & $11 \mathrm{mo}$ & $\mathrm{F}$ & Torcular AVF & Increasing head circumference & ND \\
\hline 6 & $2 y$ & $\mathrm{~F}$ & VoG, c & Gross motor delay & ND \\
\hline 7 & $3 y$ & M & VoG, c & Macrocephaly, mild dysmetria & ND \\
\hline 8 & $3 y$ & M & R frontal AVM & Headaches & ND \\
\hline 9 & $6 y$ & M & R cerebellar AVM & Seizures & ND \\
\hline 10 & $6 y$ & $\mathrm{~F}$ & L para-/intraspinal AVM & Headaches & Progressive $L$ upper extremity proximal weakness \\
\hline 11 & $9 y$ & M & R parietal AVM & Complex partial seizures & ND \\
\hline 12 & $10 y$ & $\mathrm{~F}$ & L frontal AVM & Incidental finding on $\mathrm{MRI}$ & ND \\
\hline 13 & $12 y$ & $\mathrm{~F}$ & R temporal AVM & Altered mental status & ND \\
\hline 14 & $14 y$ & $\mathrm{~F}$ & Splenial AVM & Headaches, nausea, vomiting & ND \\
\hline 15 & $18 y$ & M & Spinal AVM & $\begin{array}{l}\text { Klippel-Trenaunay syndrome, leg overgrowth and } \\
\text { weakness, cognitive impairment }\end{array}$ & ND \\
\hline
\end{tabular}

Note:-mo indicates months; d, days; VoG, vein of Galen malformation; c, choroidal type; m, mural type; ND, no (new) deficits; AVM, arteriovenous malformation; HHT, hereditary hemorrhagic telangiectasia; MRI, MR imaging; AVF, atriovenous fistula; $L$, left; $R$, right; $y$, year.

\begin{tabular}{|c|c|c|c|c|}
\hline $\begin{array}{l}\text { Patient } \\
\text { No. }\end{array}$ & Nidus Type & Shunt & Fistula & Retrograde Venous Pressurization \\
\hline 1 & Diffuse & Mixed & $\mathrm{N} / \mathrm{A}$ & No \\
\hline 2 & $\mathrm{~N} / \mathrm{A}$ & Fistulous & Single-hole & No \\
\hline 3 & $\mathrm{~N} / \mathrm{A}$ & Mixed & Dural-osseous & Reversed flow in deep venous system \\
\hline 4 & Compact & Plexiform & $\mathrm{N} / \mathrm{A}$ & No \\
\hline 5 & $\mathrm{~N} / \mathrm{A}$ & Mixed & Dural & $\begin{array}{l}\text { Cortical venous drainage via cavernous sinus to } \\
\text { SOV, facial, and scalp veins }\end{array}$ \\
\hline 6 & Compact & Mixed & N/A & Reversed flow through deep and superficial veins \\
\hline 7 & Diffuse & Mixed & N/A & No \\
\hline 8 & Diffuse & Fistulous & $\mathrm{N} / \mathrm{A}$ & No \\
\hline 9 & Compact & Plexiform & $\mathrm{N} / \mathrm{A}$ & No \\
\hline 10 & Diffuse & Plexiform & $\mathrm{N} / \mathrm{A}$ & No \\
\hline 11 & Compact & Plexiform & N/A & No \\
\hline 12 & Compact & Plexiform & $\mathrm{N} / \mathrm{A}$ & No \\
\hline 13 & Compact & Plexiform & $\mathrm{N} / \mathrm{A}$ & No \\
\hline 14 & Compact & Fistulous & $\mathrm{N} / \mathrm{A}$ & No \\
\hline 15 & Compact & Plexiform & N/A & No \\
\hline
\end{tabular}

Note:-N/A indicates not applicable; SOV, superior ophthalmic vein.

made of preoperative MR imaging, performed in all patients. All angiograms were obtained via a percutaneous transfemoral approach, with the patient under general anesthesia and in a supine position, by using a biplane fluoroscopy unit. The sheath, guiding catheter, and microcatheter were continuously flushed via a pressure bag with heparinized saline at concentrations ranging from 1000- to 4000-IU heparin/L, depending on the age of the patient. If no recent intracranial hemorrhage had occurred, after placement of the femoral sheath and obtaining a baseline activated clotting time (ACT), intravenous heparin was administered, with a target ACT of 200-350. In patients younger than 1 year or weighing $<10 \mathrm{~kg}$, a $4 \mathrm{~F}$ sheath was introduced and a $4 \mathrm{~F}$ vertebral $135^{\circ}$ angiographic catheter (Cordis, Miami Lakes, Florida) was used as a guide. In patients older than 1 year and weighing $>10 \mathrm{~kg}$, a 5F sheath and a $5 \mathrm{~F}$ Envoy catheter (Cordis) were used.

For brain lesions, 3-vessel cerebral angiography was performed, with the last vessel injected, either an internal carotid or a dominant vertebral artery, serving as a conduit for embolization. In spinal cases, relevant aortic segmental branches or subclavian branches were studied before embolization. One of 3 DMSO-compatible microcatheters,
Echelon, Marathon, or UltraFlow (all ev3) was used to selectively catheterize the feeding artery. These were advanced distally over a microwire (Transcend 0.014 inch or 0.010 inch and Synchro 0.010 inch; Boston Scientific, Natick, Massachusetts; or Mirage 0.008 inch, ev3) or under flow guidance for the UltraFlow. A hand injection was performed to ascertain that the inflow was toward the AV lesion, without arterial supply to normal brain or spinal cord.

We collected and tabulated morphologic data on the embolized AV lesions, ${ }^{5}$ with the data presented in Table 2.

\section{Transarterial Embolization Technique ("Stacking")}

In most cases, Onyx 34 was first slowly injected by using rapid gentle taps under fluoroscopic guidance, with pauses of 15 seconds to 2 minutes to create a plug around the microcatheter tip, providing the equivalent of a wedged microcatheter position. Care was taken not to allow significant reflux of Onyx up the microcatheter tip ( $<10 \mathrm{~mm}$ in a straight vessel, and $<5 \mathrm{~mm}$ in a tortuous vessel of small caliber). In most not purely fistulous cases, the Onyx 34 syringe was then exchanged for the Onyx 18, to allow 


\begin{tabular}{|c|c|c|c|c|c|c|c|}
\hline $\begin{array}{l}\text { Patient } \\
\text { No. }\end{array}$ & $\begin{array}{c}\text { No. } \\
\text { Embolizations }\end{array}$ & $\begin{array}{c}\text { Time Interval } \\
\text { Between First, } \\
\text { Last Treatment }\end{array}$ & $\begin{array}{l}\text { Total Amount of } \\
\text { Onyx (in } \mathrm{mL} \text { ) }\end{array}$ & Coils/n-BCA & $\begin{array}{l}\text { Residual/ } \\
\text { Cure }\end{array}$ & Treatment for Residual & $\begin{array}{l}\text { Cumulative X-Ray } \\
\text { Skin Entrance } \\
\text { Dose (mGy) }\end{array}$ \\
\hline 1 & 3 & $16 \mathrm{~d}$ & 6.7 & GDC and Axium coils & $P E$ & $\mathrm{~N} / \mathrm{A}$ & 2665 \\
\hline 2 & 1 & N/A & 1.3 & $\begin{array}{l}\text { GDC-18 3D and Nexus } \\
\text { (ev3) coils }\end{array}$ & Cure & No treatment, asymptomatic & 315 \\
\hline 3 & 3 & $6 \mathrm{mo}$ & 1.3 & 360-GDC soft coils & PE & Continued embolizations & 1225 \\
\hline & 1 & $\mathrm{~N} / \mathrm{A}$ & 0.8 & None & NCE & Surgery & 624 \\
\hline 5 & 6 & $9 \mathrm{mo}$ & 12.4 & GDC-18 & NCE & Continued embolizations & 3708 \\
\hline 5 & 5 & $7 \mathrm{mo}$ & 2.8 & GDC coils & NCE & N/A & 3992 \\
\hline 7 & 3 & $4 \mathrm{mo}$ & 2.3 & Axium coils & NCE & $\begin{array}{l}\text { If feasible, will re-attempt } \\
\text { in } 2-3 y\end{array}$ & 1665 \\
\hline 8 & 1 & $\mathrm{~N} / \mathrm{A}$ & 1.6 & None & PE & Surgery & 657 \\
\hline 9 & 1 & N/A & 1 & None & $\mathrm{PE}$ & Surgery & 884 \\
\hline 10 & 5 & $4 \mathrm{mo}$ & 19.9 & GDC and Axium coils & NCE & Surgery & 2508 \\
\hline 11 & 1 & $\mathrm{~N} / \mathrm{A}$ & 2.2 & None & NCE & Surgery & 1632 \\
\hline 12 & 1 & $\mathrm{~N} / \mathrm{A}$ & 1.5 & None & NCE & Surgery & 501 \\
\hline 13 & 1 & $\mathrm{~N} / \mathrm{A}$ & 0.4 & None & Cure & None & 537 \\
\hline 14 & 1 & $\mathrm{~N} / \mathrm{A}$ & 2.1 & None & NCE & Surgery & 1956 \\
\hline 15 & 2 & $2 \mathrm{mo}$ & 9.9 & None & NCE & Continued embolization & 3907 \\
\hline
\end{tabular}

Note:-PE indicates partial embolization; NCE, near-complete embolization; n-BCA, n-butyl cyanoacrylate; GDC, Guglielmi detachable coil.

better penetration of nidal vessels. In purely fistulous cases, Onyx 34 was used throughout.

The "stacking" technique is similar to the "plug and push" technique described by others. ${ }^{6}$ However, even in cases in which antegrade flow of Onyx occurred immediately, care was taken not to allow the Onyx to flow into the lesion until a solid plug was created, to allow controlled deep penetration into the lesion nidus. With this technique, single injections could devascularize an extensive lesion.

The injection length was a function of the amount of reflux, the degree of target embolization achieved, and the radiation dose. The $5 \mathrm{~F}$ Envoy allowed angiographic injections around the microcatheter to assess the degree of embolization; in the $4 \mathrm{~F}$ system, the microcatheter was occlusive. In all cases, the microcatheter was successfully withdrawn from the plug, with no cases of vessel dissection or hemorrhage. A maximum of $7 \mathrm{~mL} / \mathrm{kg}$ of contrast was used per session. Thus, some procedures were staged and resumed after at least 24 hours, to prevent contrast-induced nephrotoxicity. The x-ray skin-entrance dose delivered in each plane was reported continually during the procedure by the fluoroscopy unit and was displayed on the flat-panel screens used for embolization. Cumulative doses are reported in the final column of Table 3. The radiation dose was limited to a maximum of 1 Gy per session, wherever possible.

In selected cases of high-flow AV fistulas or where microinjection revealed a purely fistulous component of a mixed lesion, (patients 1, $2,3,5,6$, and 11), platinum coils (Guglielmi detachable coil, Boston Scientific; or Axium; ev3) were deployed as close to the point of AV shunt as possible, to reduce rapid inflow into the vein. After coil deployment, Onyx could be injected with excellent flow control, permeating through the coil mass to the shunt point. In these cases, an Echelon microcatheter was used.

The embolization result was verified for each vessel immediately after treatment and was rated as curative, nearly complete (minimal residual fistulization seen), or partial.

\section{Postprocedure Management}

Patients with devascularization of much of the lesion and large hemodynamic shifts were transferred intubated to the intensive care unit (ICU) for tight blood pressure control. Otherwise, the patient was extubated and transferred awake to the ICU. For cases with ectatic venous pouches showing flow stagnation after embolization, intravenous heparinization was maintained postprocedure for 24 hours followed by low-molecular weight Heparin for 2 weeks.

\section{Follow-Up}

Staged embolizations were scheduled with $4-6$ weeks between interventions. When embolization was followed by surgical resection, an immediate postoperative angiogram was obtained. Follow-up angiography was scheduled 6 months following definitive treatment.

\section{Results}

\section{Anatomic Results}

Seven patients were males with a median age of 3 years ( 4 days to 18 years). Among the 8 female patients, the median age was 4 years ( 7 months to 14 years). The clinical presentation was mainly a function of the patient's age and localization, and the nature of the vascular pathology. For patients 2 years of age and younger, vein of Galen malformations $(n=4)$, infantile dural AV fistulas $(n=2)$, and a right frontal AVM $(n=1)$ were found. Brain AVMs $(n=6)$ and spinal/paraspinal AVMs $(n=2)$ were the underlying pathologies in the school-aged and adolescent patients. Table 1 outlines the presenting signs and symptoms in the different age groups, and Table 2 outlines the anatomic features found on angiography.

The following illustrative cases are representative of the angiographic morphologic features encountered and demonstrate the rationale for choosing Onyx as the embolic agent, as well as strategies for its use.

\section{Illustrative Cases}

Case 1. This 5-month old male patient (patient 2 in Table 1) was prenatally diagnosed with a vein of Galen malformation. There was no cardiac failure at birth, and he was neurologically intact. He was followed with serial sonography and MR imaging, and endovascular treatment was postponed until of 5 months of age. On cerebral angiography (Fig 1), a singlehole fistula was seen.

An Echelon microcatheter was advanced via the left verte- 

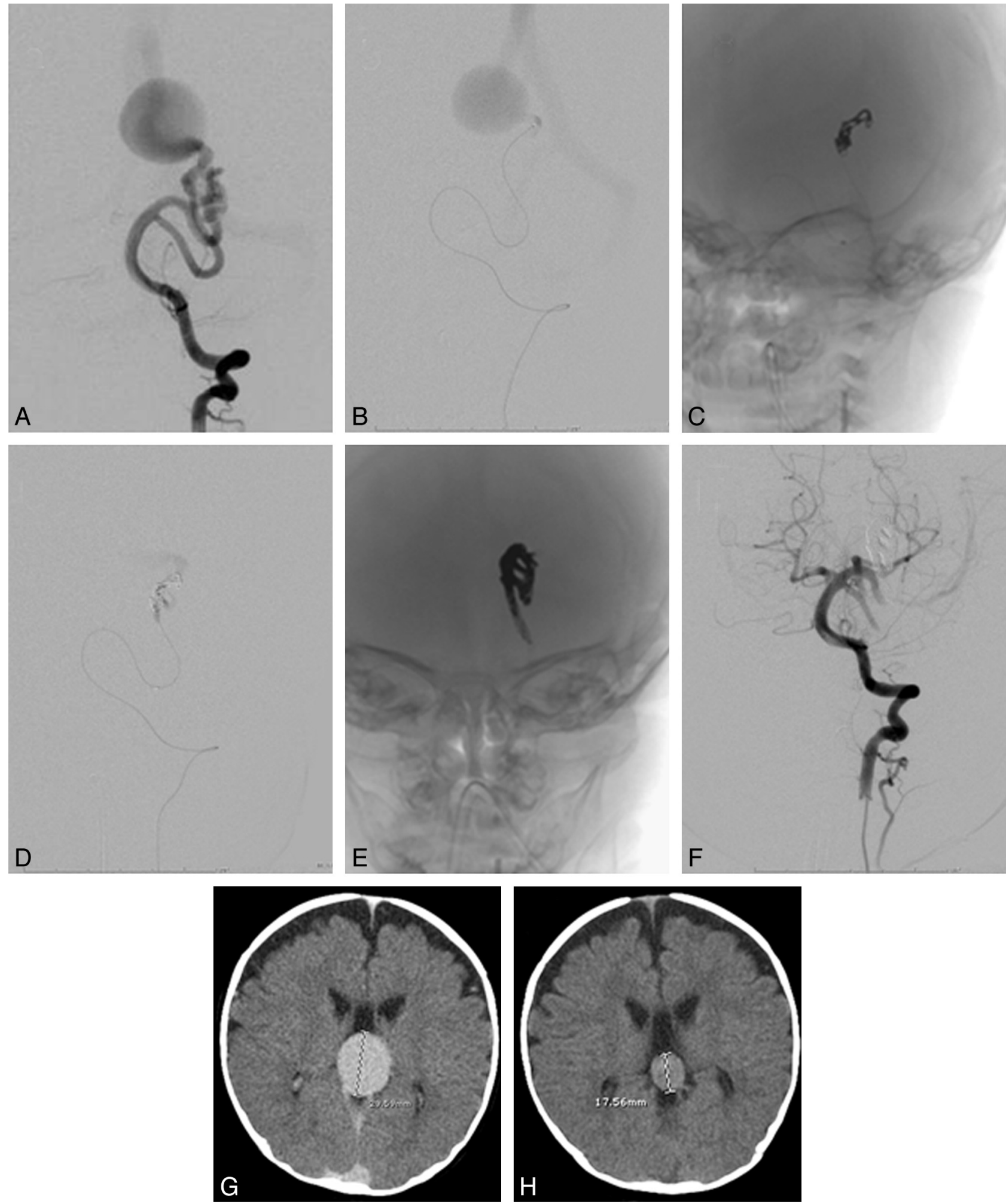

Fig 1. $A$, Frontal view of a left vertebral artery injection. $B$, Microcatheter injection close to the fistulous point shows instantaneous opacification of the venous collector and absence of nidal vessels, consistent with the mural configuration. $C-E$. Unsubtracted views after deployment of coils $(C)$ and after Onyx embolization $(E)$. Microcatheter injection at the same point after deployment of detachable coils $(D)$ demonstrates slowing of flow, with a lag before opacification of the venous system. Note how the Onyx cast reproduces the configuration of the vessels leading to the fistula in $E$. F, Postembolization image demonstrates non-opacification of the venous pouch, verifying closure of the fistula. $G$ and $H$, No venous embolization was performed, but early regression of the venous varix collecting the shunt flow is seen by comparing a pre-embolization CT $(G)$ with a CT performed 2 weeks later $(H$, study performed for an unrelated reason).

bral artery into an enlarged left posterior cerebral artery feeder. Given the very rapid flow through the single-hole fistula, detachable platinum coils were deployed within the feed- ing artery; $1.3 \mathrm{~mL}$ Onyx 18 was then injected to definitively occlude all arterial inflow into the fistula. The Onyx flowed antegrade in a controlled fashion through the interstices of the 

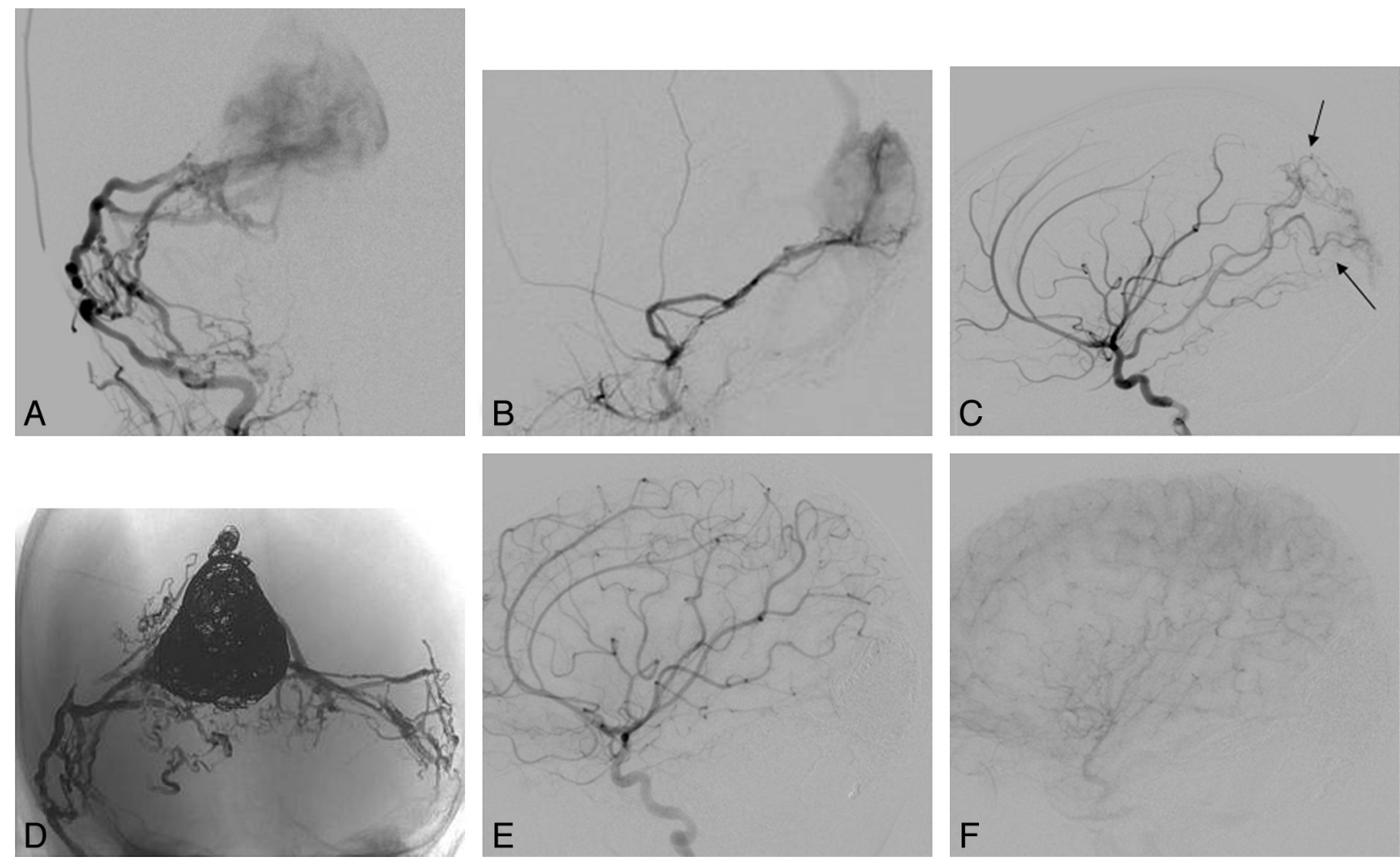

Fig 2. $A$ and $B$, Arterial supply to this infantile dural arteriovenous fistula involving the torcular in an 11-month-old child was primarily via the middle meningeal arteries bilaterally, which had a fistulous configuration at the torcular junction (frontal view in $A$, lateral view in B). C. Parasitization of pial vessels, with supply via the posterior cerebral artery (black arrows) and middle cerebral artery branches, is seen as well. $D$, Unsubtracted image in a frontal view demonstrates the large coil mass in the dysplastic midline torcular and the plexiform Onyx cast recreating the arteriovenous fistula nidus from both middle meningeal and occipital arteries. $E$ and $F$, Lateral views of a right internal carotid artery injection after embolization $(E$, early arterial; $F$, capillary phase) demonstrate nonopacification of the venous collector, with regression of the parasitized pial supply, which was never embolized.

coils, reaching the point of fistulous venous inflow with no further AV shunt present (Fig 1) and brisk opacification of the normal vertebrobasilar candelabra. The patient had a baseline intermittent right eye exotropia, which was more frequent after awakening from general anesthesia, but he was otherwise neurologically intact, with a full range of extraocular movements. The exotropia responded to patching and surgical correction, and the patient remained intact. Follow-up cross-sectional imaging demonstrated interval diminution in the caliber of the venous varix (Fig 1).

Case 2. This 11-month-old infant (patient 5 in Table 1) had facial and scalp venous prominence since 2 months of age. Macrocephaly and mild gross motor developmental delay at 1 year of age prompted MR imaging, showing a massively enlarged torcular and communicating hydrocephalus. On cerebral angiography, a torcular AV fistula was seen (Fig 2), with arterial supply via the meningohypophyseal dural tentorial arcade, the middle meningeal and occipital arteries bilaterally, and parasitized pial vessels. In the first stage of embolization, detachable platinum coils were deployed within the torcular via a transvenous route, significantly diminishing flow through the fistula. In subsequent separate stages, the posterior divisions of each middle meningeal artery and the transosseous branches of each occipital artery were embolized by using Onyx, resulting in a marked normalization of hemispheric flow, with use of the left sigmoid sinus for brain parenchymal venous drainage. The parasitized pial arterial contributions to the fistula, though never embolized, have dissipated entirely (Fig 2). The child is neurologically intact, and the macrocrania has stabilized.

Case 3. The patient was a 3-day-old neonate transferred to our institution with a diagnosis of vein of Galen malformation and cardiac failure (patient 1 in Table 1). Brain MR imaging revealed a choroidal type of vein of Galen malformation, with normal brain parenchyma, mild ventriculomegaly, and external hydrocephalus. After attempts to medically optimize the patient's management, the decision was made to undertake urgent embolization on day 4 of life. Angiography revealed fistulous segments intermixed with the nidal vessels of the AVM, with contrast opacification of normal brain parenchyma difficult to appreciate in the setting of the massive shunt (Fig 3). Embolization was aimed at the fastest flow fistulous feeders within the large lesion, by using platinum coils followed by Onyx. There was a marked improvement in the patient's vital signs as the embolization proceeded, with weaning of the pressors during the procedure.

Two days later, the patient's cardiopulmonary status worsened, and the decision was made to embolize the AVM further on day 7 of life. Platinum coils and Onyx were again used to target the fastest flow fistulous elements (Fig 3), and as before, the patient's vital signs dramatically improved during the embolization. However, after several days of stability, the patient's pulmonary hypertension worsened. The decision was made to attempt 1 further extensive embolization on day 20 of life. Onyx alone was delivered via right and left pericallosal arteries, a right posterior choroidal artery, and a right lenticu- 

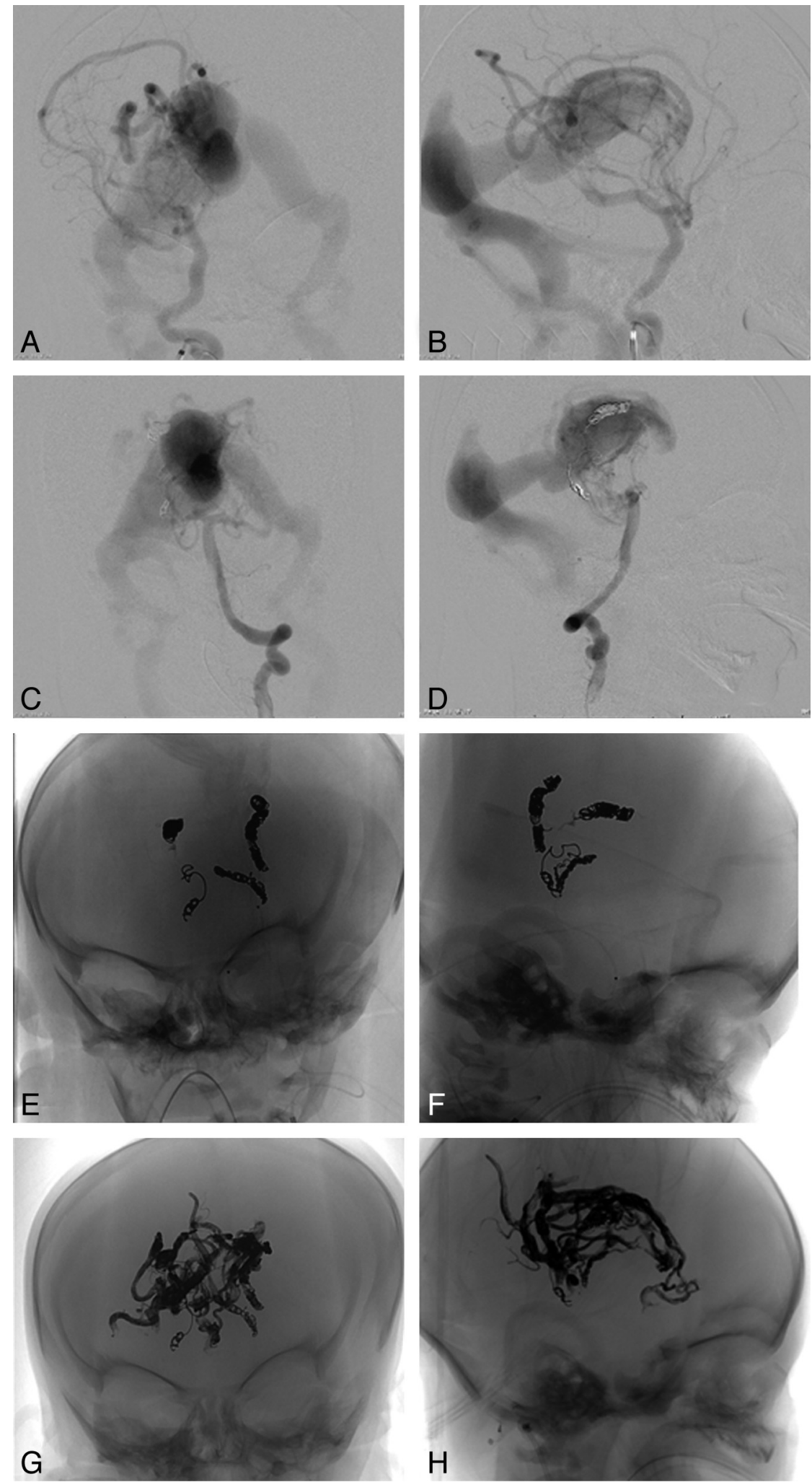

Fig 3. $A-D$, Frontal $(A)$ and lateral $(B)$ views of a right ICA injection and a left vertebral artery injection $(C$ and $D)$ on days 4 and 7 of life demonstrate rapid opacification of the ectatic median vein, making it difficult to appreciate brain parenchymal opacification of these injections. $E$ and $F$, Frontal $(E)$ and lateral $(F$ views of the coil mass and small Onyx casts deployed on days 4 and 7 of life. During each of these embolizations, the patient experienced a marked improvement in hemodynamic function, with weaning of the pressors during the procedure $G$ and $H$, Frontal $(G)$ and lateral $(H)$ views of the extensive Onyx cast delivered on day 20 of life.

lostriate feeder, with the extensive cast demonstrated in Fig 3. Brain MR imaging revealed no infarcts or other parenchymal lesions, and sensorimotor function remained intact.
During the next month, the patient's pulmonary hypertension improved slowly, all pressors were weaned, and the decision was made to attempt extubation 34 days after the last 
embolization. Unfortunately, immediately after undergoing a procedure to insert a subcutaneous intravenous catheter with the patient under general anesthesia, the patient developed high fever and a precipitous decline in liver function. All attempts at treatment were futile, and he died 3 days later.

\section{Transarterial Embolization and Outcome}

Technical Aspects. The 15 patients underwent 36 transarterial embolizations by using Onyx for AV malformations and fistulas from March 2007 through April 2009. Nine patients were embolized once, and the remaining patients underwent an average of 4.2 procedures. In 7 interventions, Onyx was used for definitive embolization after detachable coils had been deployed in high-flow situations, including vein of Galen malformations (patients 1, 2, 6, and 7), dural AV fistulas (patients $3^{7}$ and 5), and a paraspinal AVM (patient 8). Twentynine endovascular procedures were performed with Onyx as the sole embolic agent. In 3 procedures involving this cohort, coils alone were used in 1 stage of the serial embolizations (patients 3, 5, and 10); these are not included in the tally of Onyx embolizations.

We strongly favor staging embolization of complex lesions to limit both the contrast dose ( $<7 \mathrm{~mL} / \mathrm{kg}$ in all cases $)$ and the radiation exposure ( $<1$ Gy in all non-life-threatening cases) in these pediatric patients, with an interval of approximately 6 weeks between procedures. Additionally, we work with the assumption that less dramatic alterations in cerebral hemodynamics from staged embolizations result in lower potential morbidity. Patients with complex vein of Galen malformations (patients 1, 6, and 7), infantile dural fistulas (patients 3 and 5), and spinal AVMs (patients 10 and 14) fall into this category. Because of continued progression of neurologic worsening from cord compression by her AVM, despite the very complex underlying spinal/paraspinal AVM, patient 10 ultimately underwent resection, with a low level of blood loss and good outcome. Six of 7 patients with pial brain AVMs (patients 4, 8, 9, 11, 12, and 14) underwent surgery following a single embolization, with good functional outcome in every case. Patient 13 had no residual AVM after embolization via the single-vessel arterial supply. In all cases of surgically treated AVMs, no morbidity was attributable to the preoperative embolization.

The completeness of the embolization in our cohort is largely a function of the underlying pathology, as shown in Table 3. Onyx embolization resulted in the complete elimination of AV shunt in 1 patient with a mural type vein of Galen malformation and in 1 patient with a single-feeder pial AVM. Embolization was nearly complete in 9 patients and partial in 4 patients.

While there is no formal recommended ceiling on DMSO dosing, during the trials leading to FDA approval of Onyx for brain AVMs, the average administered dose was $205 \mathrm{mg} / \mathrm{kg}$ (cited by Jankowitz et al, ${ }^{8}$ though the units should be milligram per kilogram). As a rule of thumb, a dose of 1 vial per 10 pounds of patient body weight translates to a dose of $250 \mathrm{mg} /$ $\mathrm{kg}$, and we limited the dose of Onyx administered per session accordingly. The only exception to this was for the third embolization in patient 1 (illustrative case 3), who faced lifethreatening pulmonary hypertension and cardiac failure, whose dose during the extensive embolization was $1150 \mathrm{mg}$ / kg. Follow-up MR imaging revealed no parenchymal changes, his neurologic examination remained stable, and his general physiologic condition improved during the next month.

\section{Complications}

We experienced no vessel perforation, vessel dissection, unintended vessel occlusion, or stuck catheters. There were no postembolization hemorrhages or territorial infarcts. There was neither permanent neurologic morbidity nor mortality.

In two patients with vein of Galen malformation (patients 1 and 6), the high shunt flow carried a tiny stream of Onyx inadvertently into the venous side of the lesion. In patient 1 , two drops of Onyx were rapidly carried through the venous pouch to the jugular bulb while he was undergoing embolization via a branch of the right lenticulostriate artery (Fig 4). These lodged in the jugular bulb without impeding flow and with no evidence of jugular stenosis. The oxygen saturation and vital signs remained stable and unchanged through the procedure. In patient 6 , a thin strand of Onyx was noted to have extended to within the midline varix of the median vein (Fig 4), remaining attached to the cast on the arterial side without detaching. There was no change in oxygen saturation, no change in vital signs, and no radiographic or clinical sign of distal embolization.

In patient 2, the left vertebral and basilar arteries developed vasospasm after the Echelon microcatheter was pulled out of the cast. A slow infusion of $20-\mu \mathrm{g}$ nitroglycerin was administered intra-arterially for 5 minutes, and repeat angiography demonstrated complete resolution.

One patient with an extensive high-flow Galenic malformation, pulmonary hypertension, and heart failure (patient 1 , illustrative case 3 ) developed fever and fulminant hepatic failure 34 days after the last embolization, following an unrelated procedure performed with the patient under general anesthesia. His cardiopulmonary status had improved following embolization and extubation had been planned. His neurologic examination findings remained stable, and interval brain MR imaging demonstrated no parenchymal abnormalities. It is difficult to postulate a relationship between the embolization and his acute worsening more than a month later.

Patient 10 experienced exacerbation and continued progression of her left upper extremity weakness in the face of repeated embolization of her spinal/paraspinal AVM. She underwent successful resection, with significant functional recovery after rehabilitation.

In 3 infants (patients 2, 3, and 6), embolization was followed by transient symptoms that resolved within 24 hours. Patients 2 and 6, both with vein of Galen malformations, had an underlying intermittent unilateral exotropia, which was more persistent following embolization. These both improved to baseline within 24 hours, though patient 2 underwent eye patching and ultimately corrective surgery. Patient 3 awoke from 1 session of embolization with general malaise, flaccidity, and diffuse hypotonia, suggestive of prolonged neuromuscular blockade. She improved to baseline within 24 hours.

\section{Discussion}

Weber et $\mathrm{al}^{6}$ reported the efficacy of the more viscous Onyx 34 for embolizing fistulous AV shunts in adult patients with brain AVMs. In facing fistulous AV shunts in our series, we used 

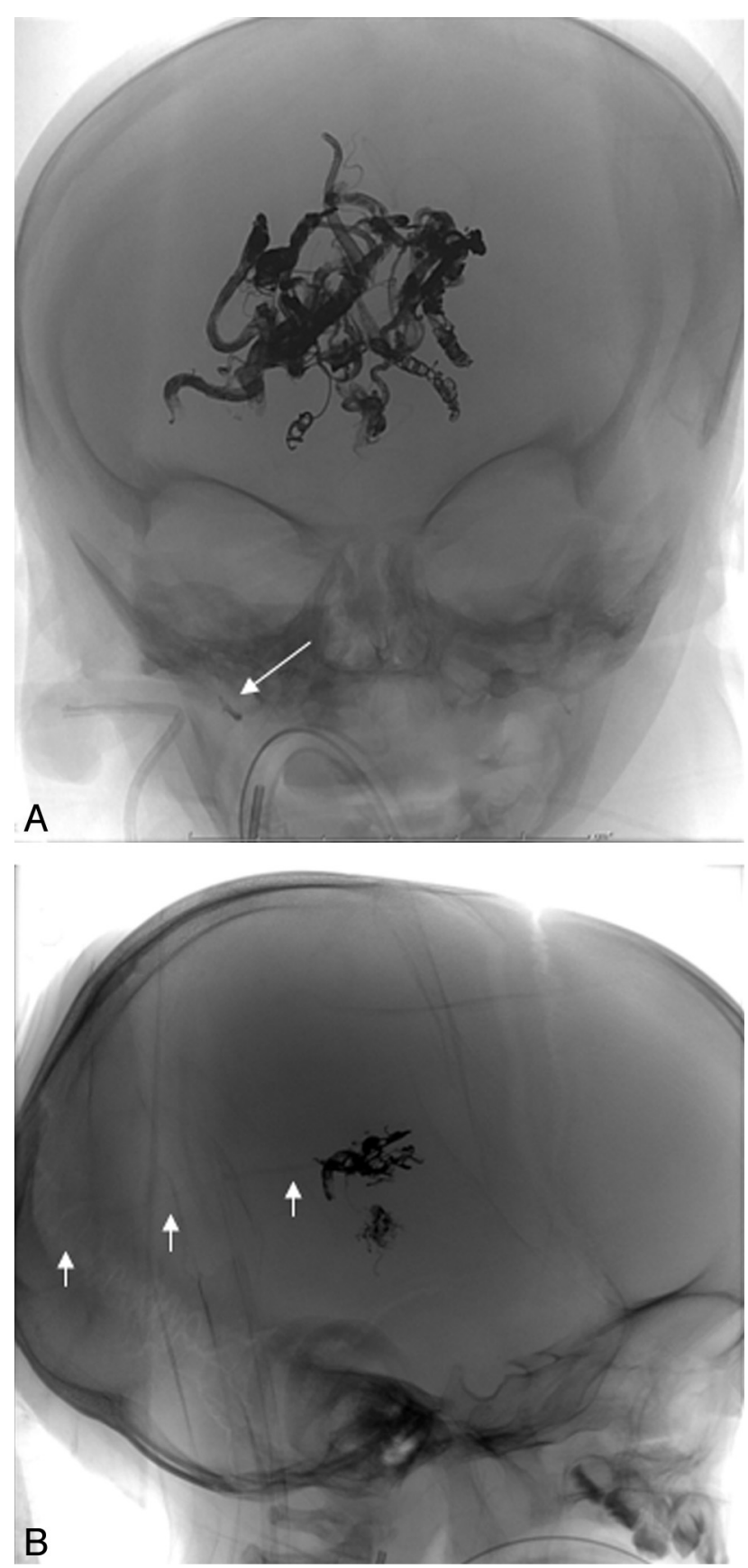

Fig 4. $A$, Frontal unsubtracted view of 2 drops of Onyx lodged in the jugular bulb without any impeding flow and without evidence of jugular stenosis, after Onyx embolization of a Galenic malformation (white arrow demonstrates the detached drops). $B$, In another vein of Galen malformation case, a thin strand of Onyx was noted to have extended to within the midline varix of the median vein (white arrows), remaining attached to the main cast.

Onyx 34 in combination with platinum coils in 7 patients. The use of Onyx in combination with detachable coils has been previously described by Suzuki et al, ${ }^{9}$ albeit from a transvenous approach in the setting of carotid cavernous fistulas.

Weber et $\mathrm{al}^{10}$ experienced 5 vessel perforations and 4 stuck microcatheters in a cohort of 47 patients treated. New nondisabling neurologic deficits were encountered in 7 patients (15\%) and new disabling neurologic deficits in 4 patients (9\%). Delayed hemorrhage after embolization occurred in 2 patients (4\%). This clinical complication rate was comparable with the series by Hamada et $\mathrm{al}^{11}$ and Jahan et al. ${ }^{4}$

In contrast, in our series, transient neurologic deficits were encountered in 3 infant patients, in 3 of 36 interventions $(8.3 \%)$, including 2 cases of transient worsening of baseline intermittent exotropia (patients 2 and 6) and 1 case of generalized flaccidity and hypotonia (patient 3 ). The symptoms resolved to baseline within 24 hours.

Experience with Onyx in managing spinal AVMs is much more limited, reflecting the relative rarity of this condition. Corkill et $\mathrm{al}^{12}$ reported immediate clinical deterioration in 9 of 21 endovascular treatment sessions by using Onyx for embolization of spinal intramedullary AVMs. Our cohort included 2 patients with paraspinal/intraspinal AVMs with epidural venous drainage. In both cases, significant intraspinal mass effect was exerted on the cord by the draining varices. One patient (patient 15) has shown mild clinical improvement in lower extremity function after staged embolization, while the other (patient 10) continued to manifest significant progressive deterioration of her upper and lower extremity weakness, worsening 3 days after extensive embolization. She underwent resection of a large paraspinal/intraspinal AVM and made a substantial recovery of upper and lower extremity strength in rehabilitation following surgery.

In our series, we did not encounter device-related technical complications such as vessel perforations, unintended vessel occlusions, or stuck catheters. No hemorrhages or territorial infarcts occurred, there was no permanent neurologic morbidity, and there was zero mortality. There were no related systemic adverse events. Herman et $\mathrm{al}^{13}$ reported perihilar edema and pulmonary hypertension as a result of embolization of Onyx into the pulmonary artery in an infant with a high-flow AV fistulous malformation. We did not encounter evidence of pulmonary or neurologic toxicity in any of our patients that could be related to DMSO. Hemodynamic and ventilatory parameters (invasive blood pressure, electrocardiography, end-tidal carbon dioxide, oxygen saturation, airway pressure monitoring) were carefully monitored throughout every procedure.

One concern related to Onyx is the potential for increased $\mathrm{x}$-ray exposure as a consequence of prolonged embolization injections. A systematic comparison of the $\mathrm{x}$-ray dose when Onyx is used versus $n$-butyl cyanoacrylate ( $n$ $\mathrm{BCA}$ ) or some other embolic agent would require 2 patient cohorts with analogous lesions, randomized to receive 1 treatment or the other. As a proxy for this idealized comparison, we compared the skin $\mathrm{x}$-ray entrance dose delivered to the Onyx cohort here (last column in Table 3) with other age-matched patients harboring complex intracranial lesions, treated by us during the same time period, by using detachable coils or $n$-BCA. The Onyx cohort received an average of $765 \mathrm{mGy} / \mathrm{session}$, while the non-Onyx group received an average of $539 \mathrm{mGy} /$ session. Both these values are below the range reported in the pediatric neurointerventional subset of the Radiation Dose in Interventional Radiology Study, ${ }^{14}$ performed before Onyx was available. Furthermore, delivery of agents other than Onyx typically requires more repeated multiple microcatheterizations of various feeders. Thus, the risk-versus-benefit consideration is that of fewer prolonged injections versus repeated access 
and potentially a greater number of total procedures. It will be important to continue following radiation-related sequelae in treated pediatric patients with high-flow intracranial vascular lesions.

The only published reports on the use of Onyx in children are a case report by Germanwala et al, ${ }^{15} 2$ cases by Eddleman et al, ${ }^{16}$ and a smaller case series by Jankowitz et al. ${ }^{8}$ Germanwala et al reported a 1-year-old child with a residual vein of Galen malformation who had been treated with coils via transarterial and transvenous routes at the age of 20 days, subsequently embolized to closure by using Onyx 18. Eddleman et al described 2 cases with infectious intracranial aneurysms treated with Onyx. Jankowitz et al report on 21 procedures in 6 patients, 4 with brain AVMs and 2 with vein of Galen malformations. They reported transient neurologic changes in 1 patient and 2 deaths within 24 hours of embolization due to intracranial hemorrhage.

We report here the largest series of Onyx embolizations in CNS AV lesions in children. The results, in terms of clinical and angiographic improvement, with a very low rate of transient morbidity and no permanent morbidity or mortality, are encouraging. More studies on the use of Onyx with longer follow-up are certainly needed to confirm both its long-term safety and efficacy in this set of patients still undergoing growth and development.

\section{Acknowledgments}

We thank Johnny Pryor, MD, for numerous helpful discussions regarding the "stacking" technique described here, and Jodi Manchester, of the Children's Hospital interventional radiology technical staff, for help with calculation of the x-ray doses for this cohort.

\section{References}

1. Taki W, Yonekawa $\mathrm{Y}$, Iwata $\mathrm{H}$, et al. A new liquid material for embolization of arteriovenous malformations. AJNR Am J Neuroradiol 1990;11:163-68

2. Terada T, Nakamura Y, Nakai K, et al. Embolization of arteriovenous malformations with peripheral aneurysms using ethylene vinyl alcohol copolymer: report of three cases. J Neurosurg 1991;75:655-60

3. Mounayer C, Hammami N, Piotin M, et al. Nidal embolization of brain arteriovenous malformations using Onyx in $\mathbf{9 4}$ patients. AJNR Am J Neuroradiol 2007;28:518-23

4. Jahan R, Murayama Y, Gobin YP, et al. Embolization of arteriovenous malformations with Onyx: clinicopathological experience in 23 patients. Neurosurgery 2001;48:984-95, discussion 995-97

5. Valavanis A, Yasargil MG. The endovascular treatment of brain arteriovenous malformations. Adv Tech Stand Neurosurg 1998;24:131-214

6. Weber W, Kis B, Siekmann R, et al. Endovascular treatment of intracrania arteriovenous malformations with Onyx: technical aspects. AJNR Am J Neuroradiol 2007;28:371-77

7. Wang $\mathrm{H}$, Oh AK, Orbach DB. Arteriovenous shunting as a new feature of PHACES: case report. J Neurosurg Pediatr 2009;3:53-56

8. Jankowitz BT, Vora N, Jovin T, et al. Treatment of pediatric intracranial vascular malformations using Onyx-18. J Neurosurg Pediatr 2008;2:171-76

9. Suzuki S, Lee DW, Jahan R, et al. Transvenous treatment of spontaneous dura carotid-cavernous fistulas using a combination of detachable coils and Onyx. AJNR Am J Neuroradiol 2006;27:1346-49

10. Weber W, Kis B, Siekmann R, et al. Preoperative embolization of intracranial arteriovenous malformations with Onyx. Neurosurgery 2007;61:244-52, discussion 252-54

11. Hamada J, Kai Y, Morioka M, et al. A mixture of ethylene vinyl alcohol copolymer and ethanol yielding a nonadhesive liquid embolic agent to treat cerebral arteriovenous malformations: initial clinical experience. J Neurosurg 2002;97:881-88

12. Corkill RA, Mitsos AP, Molyneux AJ. Embolization of spinal intramedullary arteriovenous malformations using the liquid embolic agent, Onyx: a singlecenter experience in a series of 17 patients. J Neurosurg Spine 2007;7:478-85

13. Herman TE, Siegel MJ, Vachharajani A, et al. Cerebral arteriovenous fistula to pulmonary artery Onyx embolization. J Perinatol 2007;27:238-40

14. Thierry-Chef I, Simon SL, Land CE, et al. Radiation dose to the brain and subsequent risk of developing brain tumors in pediatric patients undergoing interventional neuroradiology procedures. Radiat Res 2008;170:553-65

15. Germanwala AV, Vora NA, Thomas AJ, et al. Ethylenevinylalcohol copolymer (Onyx-18) used in endovascular treatment of vein of Galen malformation. Childs Nerv Syst 2008;24:135-38. Epub 2007 Aug 15

16. Eddleman CS, Surdell D, DiPatri A Jr, et al. Infectious intracranial aneurysms in the pediatric population: endovascular treatment with Onyx. Childs Nerv Syst 2008;24:909-15 